\title{
Letramentos acadêmicos, a paráfrase e o plágio: a produção de resenha por alunos de graduação
}

DOI: http://dx.doi.org/10.21165/el.v49i2.2562

\author{
Hélio Rodrigues Júnior ${ }^{1}$ \\ Hélio da Guia Alves Junior ${ }^{2}$
}

\section{Resumo}

O presente artigo discute a paráfrase e o plágio na perspectiva dos letramentos acadêmicos nos cursos de graduação em Educação Física, Letras e Pedagogia. Com a recorrência de situações em que, por má compreensão da paráfrase ou letramento precário, os estudantes elaboram construções textuais que podem ser tomadas como plágio, surge a problematização que norteia esta pesquisa: em que medida a paráfrase revela, de fato, uma autoria intertextual ou, ainda, marcas de plágio, comprometendo o letramento acadêmico? Desta forma, o objetivo geral é compreender algumas dificuldades de alunos na produção escrita na universidade. Recorremos aos postulados de Faraco e Tezza (2011); Fiad (2011); Fischer (2010); Fischer e Pelandré (2010); Kleiman (2005, 2007); Koch (2000); Koch, Bentes e Cavalcante (2007); Lea e Street (1998); Machado, Lousada, Abreu-Tardelli (2004); Motta-Roth e Hendges (2010); Soares (2004).

Palavras-chave: letramento acadêmico; resenha; plágio.

1 Faculdade de São Vicente (UNIBR), São Vicente, São Paulo, Brasil;

h-rodrigues-junior@uol.com.br; https://orcid.org/0000-0002-5385-6393

2 Faculdade de São Vicente (UNIBR), São Vicente, São Paulo, Brasil; hdg.jr@hotmail.com; https://orcid.org/0000-0002-5643-8656 


\title{
Academic literacies, paraphrase and plagiarism: the production of reviews by undergraduate students
}

\begin{abstract}
This article discusses paraphrase and plagiarism from the perspective of academic literacies in undergraduate courses in Physical Education, Language and Pedagogy. With the recurrence of situations in which, due to misunderstanding of paraphrase or poor literacy, students elaborate textual constructions that can be taken as plagiarism, the following question arises: to what extent does paraphrase reveal, in fact, an intertextual authorship or marks of plagiarism, compromising the academic literacy? Thus, the general objective is to understand some difficulties of students in the written production in the university. We use the postulates of Kleiman $(2005,2007)$, Soares (2004) Faraco and Tezza (2011), Fiad (2011), Motta-Roth and Hendges (2010), Machado, Lousada, AbreuTardelli (2004) and Koch, Bentes, and Cavalcante (2007).
\end{abstract}

Keywords: academic literacy; review; plagiarism.

\section{Considerações iniciais}

Este trabalho trata da paráfrase e do plágio na perspectiva dos letramentos acadêmicos nos cursos de graduação em Educação Física, Letras e Pedagogia. Deparamo-nos com situações em que, por falta de compreensão da ideia de citação ou intimidade com a escrita, os alunos incorrem em construções textuais cujo conteúdo pode ser compreendido como plágio. Por consequência, motivamo-nos a olhar as paráfrases presentes nas produções dos estudantes, identificando até que ponto esses intertextos podem ser considerados como uma cópia implícita do texto de um terceiro ou um novo entretecido constituído a partir das interações com a produção do outro.

Partimos do seguinte questionamento: em que medida a paráfrase revela, de fato, uma autoria intertextual ou, ainda, marcas de plágio, comprometendo o letramento acadêmico? Logo, nosso objetivo geral é compreender algumas dificuldades de alunos na produção escrita da universidade. Os específicos são: (i) estudar os letramentos acadêmicos; (ii) relacionar a paráfrase e o plágio à produção intertextual da resenha; (iii) refletir e propor caminhos para o desenvolvimento da produção textual acadêmica.

Recorremos aos postulados de letramentos de Kleiman $(2005,2007)$, Soares (2004) e baseamo-nos nos estudos sobre os letramentos acadêmicos de Faraco e Tezza (2011), Fiad (2011), Fischer (2010), Fischer e Pelandré (2010), Lea e Street (1998), Motta-Roth e Hendges (2010); a resenha de Machado, Lousada e Abreu-Tardelli (2004); a intertextualidade de Koch (2000) e Koch, Bentes e Cavalcante (2007) e o plágio de Schneider (1990). 
O córpus foi constituído por resenhas obtidas nas produções finais semestrais dos alunos da disciplina de Filosofia da Ciência e Pensamento Crítico dos cursos de licenciatura em Educação Física, Letras e Pedagogia. Essas produções textuais foram elaboradas com o objetivo de expor, de forma estruturada, o posicionamento crítico dos alunos em relação a ideias apresentadas por terceiros. Ao analisarmos 5 produções escritas, escolhidas aleatoriamente, levantamos a produção intertextual da paráfrase e as marcas do plágio no texto.

Concluímos que os alunos, conscientemente ou não, recorrem ao plágio na produção da paráfrase e que há alunos cuja má compreensão da ideia de plágio contribuiu para o prejuízo do próprio letramento acadêmico. Por fim, com o intuito de minimizar a ocorrência desses eventos, propomos o Laboratório de Texto como política institucional.

\section{Algumas considerações sobre os letramentos acadêmicos}

Para situarmos os letramentos acadêmicos, partimos do conceito de letramento de Soares (2004, p. 106) ao afirmar que

[...] na vida cotidiana, eventos e práticas de letramento surgem em circunstâncias da vida social ou profissional, respondem a necessidades ou interesses pessoais ou grupais, são vividos e interpretados de forma natural, até mesmo espontânea; na escola, eventos e práticas de letramento são planejados e instituídos, selecionados por critérios pedagógicos, com objetivos predeterminados, visando à aprendizagem e quase sempre conduzindo a atividades de avaliação.

A autora enfatiza a visão do letramento, no singular, como um fenômeno social e relacionado aos contextos de uso em que a língua escrita se inscreve. Não é o caso de entendermos o letramento como sinônimo de alfabetismo, circunscrito à esfera escolar.

Nesses termos, Kleiman (2005, 2006 e 2007) compreende essa atividade como um conjunto de práticas sociais que usam a escrita, enquanto sistema simbólico e enquanto tecnologia, em contextos específicos, para objetivos específicos. O letramento aqui é destinado a desenvolver no sujeito uma autonomia do conhecimento da língua.

A noção de letramento, logo, é levada à pluralidade - letramentos - uma vez que a escrita é usada em diversos lugares com vistas à interação do sujeito com o mundo, inclusive práticas de escritas que a escola desvaloriza como aquelas das redes sociais, das múltiplas linguagens da internet - os multiletramentos.

Nessa perspectiva dos letramentos como práticas sociais e influenciados pelos estudos de Lea e Street (1998), focamos o contexto da escrita na universidade e suas práticas específicas, denominada letramentos acadêmicos. 
Os autores propõem três modelos em que abordam as várias e diferentes práticas de letramento na universidade. São eles: (i) modelo das habilidades - o aluno aprende e desenvolve habilidades na universidade e as transfere para as situações de leitura e de escrita, não considerando o que desenvolveu na escola, por exemplo. Se ele apresenta dificuldades ao ler e escrever, é considerado como um aluno deficitário. O problema está no aluno. (ii) modelo da socialização acadêmica - há uma preocupação com a falta de conhecimentos que o aluno traz sobre as práticas de leitura e de escrita da universidade e, logo, o professor fica com a responsabilidade de ensinar as leituras e as escritas valorizadas na esfera acadêmica. A solução está no professor. (iii) modelo do letramento acadêmico - as práticas de leitura e de escrita têm um valor na universidade e precisam ser compreendidas pelos envolvidos, implicando relações de poder entre os sujeitos. A noção de identidade e a forma como os sujeitos se relacionam com o conhecimento vêm à tona. As perspectivas etnográficas se envolvem com o contexto acadêmico, isto é, aluno e professor, juntos, lidam com a linguagem (LEA; STREET, 1998).

Por sua própria configuração transformadora, o modelo de letramento acadêmico é, portanto, o mais discutido e assumido nas práticas da leitura e da escrita, atualmente, na universidade.

No Brasil, Fiad $(2011,2013)$ desenvolve pesquisas que visam a desconstruir a tese de que os estudantes chegam à universidade sem saber escrever, questionando a visão de escrita que subjaz a essa crença - escrita como uma habilidade genérica, absoluta e aplicável a qualquer contexto. Segundo a autora,

O mito de que o aluno deve vir pronto para a universidade para ler e escrever deriva da visão de que letramento implicaria fundamentalmente o domínio de um conjunto de competências de leitura e escrita que os alunos têm de adquirir para depois transferi-las para outros contextos. Essa crença, no entanto, ofusca o fato de que os alunos universitários podem ter um bom domínio da língua, mas isso não os leva necessariamente a terem um bom domínio dos gêneros da esfera acadêmica, ou seja, como não existe uma fase de letramento ou um único letramento, são legítimas suas dificuldades para as práticas dos gêneros acadêmicos. (FIAD, 2013, p. 471).

Com isso, podemos alargar a compreensão de que os letramentos acadêmicos em contexto brasileiro já se situam na perspectiva etnográfica aliada a uma perspectiva dialógica como uma possibilidade de construir uma articulação entre o texto e o contexto na abordagem da escrita na universidade. É o que encontramos nos trabalhos de Fischer (2010) e Fischer e Pelandré (2010) ao articularem os estudos dos letramentos acadêmicos com a abordagem bakhtiniana de entendimento da linguagem, levando em consideração que a concepção dialógica da linguagem é o que encaminha a escrita em situações de letramentos acadêmicos. 
Para tanto, Faraco e Tezza (2011) produzem um livro didático, na concepção dialógica da linguagem de Bakhtin, que propõe um trabalho com a escrita na universidade acompanhado de discussões discursivas que propiciam ao aluno uma aprendizagem à luz das múltiplas linguagens sociais que o circundam. Nas palavras dos autores, o livro tem como objetivo principal "oferecer uma abordagem inovadora da produção de textos e da língua padrão" (FARACO; TEZZA, 2011, p. 7).

Nessa esteira, Motta-Roth e Hendges (2010, p. 10) criam material didático que tem como objetivo "oferecer a escritores iniciantes subsídios que os auxiliem no processo de produção de textos acadêmicos no contexto de pesquisa comumente experimentado na universidade".

Refutamos concepções tradicionais de ensino assentadas em modelos autônomos, monológicos e optamos pela construção de alternativas em que o dialogismo passa a ser revestido como o objetivo a ser percorrido nas práticas de letramentos na universidade. Assim, a planificação textual dos gêneros que circulam na universidade se constitui a favor da adequação da linguagem, do contexto de produção e de publicação, dos efeitos de sentido pretendidos na situação comunicativa.

\section{A paráfrase, a intertextualidade e o plágio}

Nas práticas dos letramentos acadêmicos, a paráfrase é uma atividade recorrente. Para Fuchs (1982), a paráfrase é a equivalência formal entre frases, considerando a manutenção da verdade do enunciado, organizada a partir de postulados lógicos; a paráfrase se constitui por meio dos significados entre o enunciado primeiro e o enunciado segundo, ambos entrelaçados por uma relação sinonímica; a paráfrase é uma atividade de reformulação do que foi posto, podendo variar de acordo com o contexto de produção.

A autora, por outras palavras, reforça que a paráfrase, com base na lógica, constituise por equivalência, uma vez que compartilha aspectos em comum, como as relações sintáticas, para a manutenção do mesmo sentido. A paráfrase também se estabelece na partida de uma ideia principal em que se anexam ideias secundárias por meio do sinônimo. Porém, a sinonímia não é suficiente para a garantia da manutenção do significado, já que a identidade referencial deve ser assegurada não só pelo novo referente, mas, também, pelo sentido de base que deve ser idêntico.

Destacamos que Fuchs (1982) levanta a problemática de que a parafrasagem promovida pela equivalência dada pela sinonímia semântica limita-se à ordem dos enunciados, renunciando à percepção de que promove uma relação atualizada do discurso. Trata-se de abordar a paráfrase, no plano do discurso, como atividade de reformulação em que o conteúdo é restaurado em um novo texto. 
Sendo assim, a paráfrase é uma ocorrência de intertextualidade. A intertextualidade é um dos fatores de textualidade. Sobre a intertextualidade, Koch (2000, p. 46) comenta:

Todo texto é um objeto heterogêneo, que revela uma relação radical de seu interior com seu exterior; e, desse exterior, evidentemente, fazem parte outros textos, que Ihe dão origem, que o predeterminam, com os quais dialoga, que retoma, a que alude, ou a que se opõe.

Isso significa que, ao escrever o texto, o locutor recorre a experiências anteriores de sua vida, retomando-as na produção, citando explicitamente, ou não, essas ocorrências. Logo, a intertextualidade pode ser implícita ou explícita.

A intertextualidade será explícita quando, no próprio texto, é feita menção à fonte do intertexto, isto é, quando um outro texto, ou um fragmento é citado, é atribuído a outro enunciador; ou seja, quando é reportado como tendo sido dito por outro ou por outros generalizados ("Como diz o povo...", "Segundo os antigos..."). É o caso das citações, referências, menções, resumos, resenhas e traduções; em textos argumentativos, quando se emprega o recurso à autoridade (KOCH; BENTES; CAVALCANTE, 2007).

Chamamos a atenção de que as interconexões no texto devem ficar claras e com as devidas fontes referenciadas. Caso contrário, podemos incorrer num furto intelectual, no plágio.

Segundo Schneider (1990, p. 47-48),

O plágio designa um comportamento refletido que visa o emprego dos esforços alheios e a apropriação fraudulenta dos resultados intelectuais de seu trabalho. [...] o plágio se distingue da criptomnésia, esquecimento inconsciente das fontes, ou da influência involuntária, pelo caráter consciente do empréstimo e da omissão das fontes. É desonesto plagiar. O plagiário sabe que o que faz não se faz.

Evidenciamos que o plágio tira o reconhecimento daquele que tem a autoria do trabalho, ou seja, a autoridade de quem escreve, de quem realiza a atividade. Isto traz danos na constituição da identidade de autoria do texto, cala a voz de quem é retomado no texto.

\section{A produção de resenha na graduação: uma questão de paráfrase ou de plágio}

O contexto da pesquisa se dá no primeiro semestre de 2019, em uma faculdade privada localizada no litoral de São Paulo, com os alunos dos cursos de licenciatura em Educação 
Física (n. 47), Letras (n. 38) e Pedagogia (n. 65), no escopo da disciplina de Filosofia da Ciência e Pensamento Crítico, em que solicitamos aos alunos organizados em grupo, como uma das atividades de avaliação, a produção coletiva de uma resenha.

Compreendemos a resenha como

[...] um gênero que pode ser chamado por outros nomes, como resenha crítica, e que exige que os textos que a ele pertençam tragam informações centrais sobre os conteúdos e sobre outros aspectos de outro(s) texto(s) lido(s) - como, por exemplo, sobre o seu contexto de produção e recepção, sua organização global, suas relações com outros textos etc., e que, além disso, tragam comentários do resenhista não apenas sobre os conteúdos, mas também sobre todos esses outros aspectos. (MACHADO; LOUSADA; ABREU-TARDELLI, 2004, p. 14).

Em um primeiro momento, a fim de subsidiar o norteamento teórico do presente artigo, realizamos uma pesquisa bibliográfica que forneceu o embasamento necessário para o desfecho da pesquisa quantiqualitativa (CHIZZOTTI, 2003) que resultou nas análises do córpus.

No total, participaram 150 alunos, os quais se dividiram em grupos com até cinco membros, produzindo coletivamente um total de 41 resenhas obtidas em suas produções finais semestrais da disciplina mencionada.

Essas produções textuais foram elaboradas com o objetivo de expor, de forma estruturada, o posicionamento crítico dos alunos em relação a ideias apresentadas por terceiros em livros escolhidos por eles, depois de os terem lido e debatido a respeito, contrastando as percepções individuais de cada integrante do grupo com os demais.

Da amostra geral, 5 produções escritas foram escolhidas aleatoriamente para constituir o córpus do trabalho. Analisamos as marcas de plágio no texto, entendidas como evidências de "emprego dos esforços alheios e a apropriação fraudulenta dos resultados intelectuais de seu trabalho" (SCHNEIDER, 1990, p. 47) e a produção intertextual da paráfrase, compreendida como um exercício de interpretação e reformulação de um texto-fonte, que dá origem a um novo enunciado (FUCHS, 1982).

\section{Análise do córpus}

Os quadros a seguir representam as transcrições dos fragmentos analisados, as quais preservam o conteúdo sem alterações ortográficas ou sintáticas. O texto está disposto nas linhas de acordo com sua presença no excerto original. Na sequência, vêm as análises da produção intertextual da paráfrase e as marcas de plágio. 
Quadro 1. Fragmento de resenha da amostra

\begin{tabular}{|l|l|}
\hline 1 & Os países que eliminaram a simpatia pela pobreza, presente em nossa \\
\hline 2 & cultura até hoje não o fizeram graças à intervenção estatal, mas pela prática de \\
\hline 3 & uma economia livre, baseada na valorização do trabalho, apreço aos bem- \\
\hline 4 & -sucedidos, no reconhecimento da legitimidade do lucro, enfim, valores todos \\
\hline 5 & contrários aos que foram legados à força pela inquisição. "Num ambiente em que \\
\hline 6 & a lgreja prometia salvas as almas e o Estado prometia salvar os homens, os \\
\hline 7 & Brasileiros foram ensinados a acreditar que deveriam ser auxiliados por algum tipo \\
\hline 8 & de autoridade, política ou religiosa" (GARSCHAGEN, 2018, 53). \\
\hline
\end{tabular}

Fonte: Elaboração própria

Produção intertextual da paráfrase: o texto apresenta uma citação direta demarcada por aspas e com as devidas referências (I. 5 - 8). Há marcas de intertextualidade explícita (I. 5 - 8) e implícita (I. 1 - 5). Marcas do plágio no texto: há a presença explícita de discurso de um terceiro, a qual contém as indicações de autoria adequadas (l. 1 - 5), porém, ainda falta a presença da abreviação de página "p.", conforme exigem as normas técnicas. Na paráfrase, como é de se esperar, há a presença implícita do discurso de outro autor (I. $1-5)$.

Entre as linhas 1 e 5, notamos linguagem e seleção lexical diferentes das que o aluno costuma empregar no cotidiano, mas não há indicação explícita de intertextualidade ou de autoria. Dizer a quem pertence a ideia na continuação do texto com a citação direta não exclui a omissão de autoria no início do fragmento, já que um leitor menos atento provavelmente o assumiria como texto do aluno. Portanto, caracterizamos a presença de plágio, pois há uma apropriação da produção de um terceiro sem os devidos créditos. Do ponto de vista do letramento acadêmico, tentando identificar as fragilidades de formação do aluno, excluindo, portanto, a possível intenção de plagiar o autor, podemos perceber a provável má compreensão do uso dos meios adequados para a realização da paráfrase, resultando em uma produção comprometida. Por um lado, reconhecemos a gravidade do plágio e, por outro, destacamos que o professor é levado a proporcionar ao aluno o desenvolvimento de competências com vistas à superação de quaisquer dificuldades com a escrita acadêmica e com vistas à erradicação do plágio. 
Quadro 2. Fragmento de resenha da amostra

\begin{tabular}{|l|l|}
\hline 1 & O princípio republicano, diferente da monarquia, não encontra poder na pessoa de \\
\hline 2 & um só, como pode, às vezes, parecer no presidencialismo. Primeiro, porque as \\
\hline 3 & funções do Estado são separadas em legislativa, executiva e judiciária; segundo \\
\hline 4 & porque o Presidente da República exerce mandato e conforme dispõe a Carta \\
\hline 5 & Política brasileira, de 4 em 4 anos há eleições; ele é escolhido. \\
\hline 6 & Desde 1889 nosso País já teve diferentes repúblicas iniciando-se com a velha ou \\
\hline 7 & república da espada (1889-1930); república nova ou era Vargas (1930-1945); \\
\hline 8 & república contemporânea de 1945 até os dias atuais. \\
\hline
\end{tabular}

Fonte: Elaboração própria

Produção intertextual da paráfrase: o texto não apresenta citações. Não há marcas de intertextualidade. Marcas do plágio no texto: há a ocorrência evidente de discurso de um terceiro, a qual não traz indicações de autoria (l. 1 - 8). A seleção lexical e o estilo de escrita rompem completamente com os adotados no restante da resenha.

Tendo em vista que não houve qualquer tentativa de indicar o autor, omitindo-se os créditos pelo texto, podemos considerar o excerto como uma exata ocorrência de plágio vulgar, já que nem sequer foi feita qualquer alteração na escrita original ou reformulação de ideias do texto-fonte, que foi apenas copiada e colada. Neste caso, não se trata de uma má compreensão das normas técnicas e mecanismos de indicação de autoria e paráfrase, pois foram corretamente empregados ao longo da resenha. Compreendemos, portanto, um uso mal-intencionado e de apropriação indevida da produção de outrem. Dentro do letramento acadêmico, essa prática deve ser combatida, pois causa prejuízos não apenas para o plagiador, mas para aqueles que têm suas obras copiadas sem os devidos créditos, resultando em uma prática criminosa.

Quadro 3. Fragmento de resenha da amostra

\begin{tabular}{|l|l|}
\hline 1 & Este trabalho visa buscar um posicionamento em relação a obra "Guia \\
\hline 2 & politicamente incorreto da história do Brasil" de Leandro Narloch. Sua primeira \\
\hline 3 & edição foi publicada em 2009. Porém, o literato encontrou, em meio aos seus \\
\hline 4 & novos estudos, uma vontade incessante de revisar e ampliar o que já tivera \\
\hline 5 & escrito. Desta forma, publicada pela editora Leya, em 2011, a segunda edição \\
\hline 6 & do mesmo livro ganha forma. Neste, o próprio autor explica a necessidade de \\
\hline 7 & uma nova edição. "A primeira edição deste livro já chegava as livrarias, mas \\
\hline 8 & ideias sobre ele não paravam de bater à porta. Novas histórias e novos \\
\hline
\end{tabular}

Fonte: Elaboração própria 
Produção intertextual da paráfrase: o texto apresenta uma citação direta demarcada por aspas e com as devidas referências (I. 7 - 8). Percebemos marcas de intertextualidade explícita (l. $7-8)$ e implícita (l. $1-7)$. Marcas do plágio no texto: há a presença explícita de discurso de um terceiro, contendo as indicações de autoria adequadas (I. 7 - 8). Não consta indicação de paráfrase, mas notamos a presença implícita do discurso de outro autor.

Da linha 1 até o início da citação direta na linha 7, percebemos que os alunos trouxeram informações as quais eles não poderiam ter em mãos se não fosse por meio de pesquisa em fontes externas, mesmo assim, não houve indicação de onde elas foram extraídas. Os alunos acreditam que, ao reformular um parágrafo do texto-fonte, preservando as ideias do autor, não se incorre em plágio. Esse equívoco se dá pela má compreensão da paráfrase e da construção de citações indiretas. Notamos, do ponto de vista do letramento acadêmico, que mesmo quando não se está mal-intencionado, é possível incorrer em construções com referenciação comprometida.

Quadro 4. Fragmento de resenha da amostra

\begin{tabular}{|l|l|}
\hline 1 & O tipo de cultura política estabelecida aqui colaborou decisivamente para \\
\hline 2 & desenvolver na sociedade uma mentalidade estatista, de dependência e \\
\hline 3 & servidão. Além da infantilização criada por meio de decisões de governo que \\
\hline 4 & incidem diretamente sobre os modos de vida e as condutas, os brasileiros \\
\hline 5 & abriram mão de sua responsabilidade individual de conduzir a própria vida para \\
\hline 6 & atribui-la ao Estado. A partir daí é possível entender por que tanta gente pede \\
\hline 7 & espera que o governo resolva os problemas sociais, políticos e econômicos. \\
\hline
\end{tabular}

Fonte: Elaboração própria

Produção intertextual da paráfrase: o texto não apresenta citações. Não há marcas de intertextualidade. Marcas do plágio no texto: há a ocorrência evidente de discurso de um terceiro, a qual não contém indicações de autoria (l. 1 - 7). A seleção lexical e o estilo de escrita rompem completamente com os adotados no restante da resenha.

Consideramos que não houve tentativa de indicar o autor, omitindo-se os créditos pelo texto, podemos considerar o excerto como uma exata ocorrência de plágio vulgar, já que não houve alteração. Assim como no segundo fragmento analisado, não se trata de uma má compreensão dos recursos de indicação de autoria, já que foram corretamente empregados ao longo da resenha. Trata-se, portanto, de um uso mal-intencionado e de apropriação indevida da produção de outrem. Como já foi colocado, durante o letramento acadêmico, essa prática deve ser combatida, pois resulta em prejuízos para o plagiador e para os plagiados. 
Quadro 5. Fragmento de resenha da amostra

\begin{tabular}{|l|l|}
\hline 1 & Olavo de Carvalho considera o livro fundamental para a formação não só da \\
\hline 2 & inteligência e do espírito crítico mais também do caráter de todos, achando a \\
\hline 3 & moralidade uma firmeza racional sem avaliar as palavras de maneira crítica, \\
\hline 4 & contando suas histórias em relação a "Esquerda" explicando o grande motivo \\
\hline 5 & desse assunto ter em seu livro dizendo as simples palavras "Eu era de \\
\hline 6 & esquerda na época passada esse livro me levou a refletir sobre assuntos da \\
\hline 7 & política e sociedade tendo uma visão mais completa da realidade e de vocês \\
\hline 8 & mesmos" Ele acha esse livro um dos seus melhores começando pelo seu \\
\hline 9 & título, explicando o porquê deu este nome ao livro sabendo que haveria críticas \\
\hline 10 & só pelo título e a sua única explicação foi que os leitores precisam ter um \\
\hline 11 & pouco de paciência e lê até o começo da página antes de criticar o título de seu livro [...] \\
\hline
\end{tabular}

Fonte: Elaboração própria

Produção intertextual da paráfrase: o texto apresenta uma citação direta demarcada por aspas, mas sem as devidas referências (I. 5 -8). Há marcas de intertextualidade explícita (I. 5 - 8) e implícita (I. 1- 5; 8 - 11). Marcas do plágio no texto: há a presença explícita de discurso de um terceiro, a qual contém indicações de autoria inadequadas (I. 5 - 8). Nas paráfrases, podemos notar a presença implícita do discurso de outro autor (I. 1-5; 8-11), mas a materialidade do texto não possibilita estabelecer os limites entre o que o aluno escreveu e o que é propriamente intertextual.

Entre as linhas 1 e 5, há a indicação de paráfrase, tendo um discursivo indireto explícito, mas não se encontra presente a indicação de ano da obra mencionada. Na tentativa de construção de citação direta, linhas 6 a 8, todas as informações necessárias para indicação de autoria estão ausentes, pois o aluno considera que a menção ao nome do autor no começo do parágrafo seja suficiente. Desta forma, mesmo estando comprometido em não se apropriar indevidamente do trabalho de terceiros, o aluno não demonstrou domínio sobre o uso das citações de acordo com as normas técnicas, evidenciando um caso em que é necessário reforçar seu letramento acadêmico.

Tendo em vista a análise do córpus apresentado, percebemos a ocorrência constante de dificuldades de compreensão do uso da paráfrase, as quais costumam trazer as indicações de autoria, bem como das normas técnicas empregadas nas citações diretas e indiretas, pois os indicadores exigidos, como sobrenome do autor, ano da edição do livro e página, costumam estar ausentes ou incompletos. 
Ademais, quando abordados a respeito de suas produções, os alunos relatam desconhecimento das normas, incompreensão dos termos ou falta de comprometimento de um ou mais integrantes do grupo com o uso ético das informações levadas para o texto.

A despeito dessa problemática na sala de aula, ressaltamos que a recorrência do plágio nas produções dos alunos ora é tratada com parcimônia, ora como crime. Cabe-nos enfatizar que reconhecemos tanto a falta de domínio da construção da paráfrase de alguns, quanto a intenção criminal do plágio de outros, desveladas por nós como um revés a ser enfrentado pelo letramento.

\section{Considerações finais}

Observamos que, de fato, há ocorrências que podem ser consideradas como plágio nas produções textuais analisadas, as quais, em sua maioria, decorrem de má compreensão do conceito e/ou do emprego da paráfrase. Além disso, percebemos a interferência de um domínio parcial dos meios de citação e referência de autores nas resenhas às quais tivemos acesso.

Não devemos, portanto, afirmar que esses equívocos na construção decorram de má intenção por parte de quem os escreve, já que nem sempre os alunos estão cientes de estarem omitindo o empréstimo de ideias de terceiros, conforme as recorrências nos textos analisados, já que muitos apresentam reflexos de uma má formação na educação básica.

Porém, o plágio se mantém nas produções escritas que circulam na universidade, revelando-se, assim, um enorme desafio para o professor e para o sujeito em formação, uma vez que as atividades de leitura e escrita assentadas na perspectiva dos letramentos acadêmicos favorecem a construção de estratégias metodológicas com vistas à superação dessa ilegalidade, a boas práticas científicas, à perpetuação dos trabalhos autorais e ao desenvolvimento da autonomia do aluno, viabilizando produções aceitáveis dentro da esfera acadêmica.

Do ponto de vista das possibilidades de implementação de soluções no contexto estudado, vemos que é necessário buscar alternativas para amenizar a recorrência do plágio nas produções textuais dos estudantes de graduação, o que nem sempre pode ser feito dentro da carga horária da disciplina em questão.

Depois de buscar compreender o contexto no qual os alunos estão inseridos, de onde decorre parte de seus obstáculos, como a falta de contato com a literatura acadêmica e a falta de prática da escrita própria desta esfera, propomos a criação de uma política 
institucional extracurricular que permita o desenvolvimento de competências nos estudantes almejando o domínio dos gêneros acadêmicos, a qual, de preferência, ocorra fora do horário das aulas.

Ao retomarmos a compreensão dos letramentos como uma prática social, buscando a emancipação do aluno enquanto sujeito socialmente estabelecido e autônomo, concluímos que não devemos pressupor que ele chegará à universidade munido de todos os recursos e habilidades necessários para uma performance irretocável no campo acadêmico, o que daria suporte a uma visão aristocrática das relações pedagógicas, cuja exclusão daqueles que não cumprem com as expectativas seria legitimada.

Em vez disso, propomos uma revisão das práticas adotadas até então com vistas a promover uma atmosfera que viabilize a aquisição das competências e compreensão dos desdobramentos de suas práticas dentro da academia, garantindo, desta forma, o desempenho almejado com os gêneros acadêmicos.

\section{REFERÊNCIAS}

CHIZZOTTI, A. A pesquisa qualitativa em ciências humanas e sociais: evolução e desafios. Revista Portuguesa de Educação, Braga, v. 16, n. 2, p. 221-236, 2003.

FARACO, C. A.; TEZZA, C. Prática de texto para estudantes universitários. São Paulo: Vozes, 2011.

FIAD, R. S. A escrita na universidade. Revista da ABRALIN, v. Eletrônico, n. esp., p. 357-369, 2011.

FIAD, R. S. Reescrita, dialogismo e etnografia. Linguagem em (Dis)curso. Tubarão, Santa Catarina, v. 13, n. 3, p. 463-480, set./dez. 2013.

FISCHER, A. Sentidos situados em eventos de letramento na esfera acadêmica. Educação, Santa Maria, v. 35, n. 2, p. 215-228, maio/ago. 2010.

FISCHER, A.; PELANDRÉ, N. Letramento acadêmico e a construção de sentidos nas leituras de um gênero. Perspectiva, Florianópolis, v. 28, n. 2, 569-599, jul./dez. 2010.

FUCHS, C. La paraphrase. Paris: Presses Universitaire de France, 1982. 
HILGERT, J. G. Procedimentos de reformulação: a paráfrase. In: PRETI, D. Análise de textos orais. São Paulo: Humanitas, 1997.

KLEIMAN, A. B. Oficina de leitura: teoria e prática. Campinas: Pontes, 2007.

KLEIMAN, A. B. Modelos de letramento e as práticas de alfabetização na escola. In: KLEIMAN, A. B. (org.). Os significados do letramento: uma nova perspectiva sobre a prática social da escrita. Campinas: Mercado de Letras, 2006.

KLEIMAN, A. B. Preciso ensinar o letramento? Não basta ensinar a ler e a escrever? Campinas: UNICAMP/MEC, 2005.

KOCH, I. G. V. Argumentação e linguagem. São Paulo: Cortez, 2000.

KOCH, I. G. V.; BENTES, A. C.; CAVALCANTE, M. M. Intertextualidade: diálogos possíveis. São Paulo: Cortez, 2007.

KRISTEVA, J. Introdução à semánalise. Tradução Lúcia Helena França Ferraz. 3. ed. revista e aumentada. São Paulo: Perspectiva, 2012 [1969].

LEA, M. R.; STREET, B. Student Writing in higher education: an academic literacies approach. Studies in Higher Education, London, v. 23, n. 2, p. 157-172, jun. 1998.

MACHADO, A. R.; LOUSADA, E.; ABREU-TARDELLI, L. S. Resenha. São Paulo: Parábola, 2004.

MOTTA-ROTH, D.; HENDGES, G. R. Produção textual na universidade. São Paulo: Parábola Editorial, 2010.

SCHNEIDER, M. Ladrões de palavras: ensaio sobre o plágio, a psicanálise e o pensamento. Campinas: UNICAMP, 1990.

SOARES, M. Letramento e escolarização. In: RIBEIRO, V. M. (org.). Letramento no Brasil. São Paulo: Global, 2004. 